\title{
estimativa das Perdas de Produtividade de Grãos em Cultivares de ARroz (Oryza sativa) Pela InTERFerênCIA do CAPIM-ARROZ (Echinochloa spp.) ${ }^{1}$
}

\author{
Estimation of Grain Yield Loss in Rice (Oryza sativa) Cultivars Due to Interference by \\ Barnyardgrass (Echinochloa spp.)
}

\begin{abstract}
GALON, L. ${ }^{2}$, AGOSTINETTO, D. ${ }^{3}$, MORAES, P.V.D. ${ }^{2}$, TIRONI, S.P. ${ }^{4}$ e DAL MAGRO, T. ${ }^{2}$
RESUMO - Objetivou-se com este trabalho avaliar o grau de interferência do capim-arroz em cultivares de arroz irrigado e comparar variáveis explicativas, visando identificar aquela que propicia melhor ajuste dos dados a modelo matemático. Para isso, foi conduzido experimento a campo no ano agrícola 2005/06, com cultivo de arroz em sistema convencional. Os tratamentos foram constituídos por seis cultivares de arroz com diferentes durações do ciclo de desenvolvimento e por dez populações de capim-arroz. As variáveis respostas foram avaliadas aos 28 dias após a emergência do arroz. O modelo da hipérbole retangular foi utilizado para descrever a relação entre perda de produtividade de grãos de arroz e variáveis explicativas população de plantas, massa da matéria seca da pare aérea, cobertura do solo e área foliar. As perdas de produtividade de grãos de arroz devidas à interferência do capimarroz podem ser estimadas satisfatoriamente pelo modelo da hipérbole retangular. Os cultivares de arroz IRGA 421, 416 ou 417 foram os mais competitivos, obtendo-se adequado ajuste dos dados ao modelo testado para todas as variáveis avaliadas. A variável população de plantas de capim-arroz apresenta melhor ajuste ao modelo do que massa da matéria seca da parte aérea, cobertura do solo ou área foliar.
\end{abstract}

Palavras-chave: competição, modelo empírico, variáveis explicativas.

\begin{abstract}
The objectives of this research were to evaluate the level of barnyardgrass interference in flooded rice cultivars and to compare explicative variables aiming to identify the variable providing better data adjustment to a mathematical model. Thus, a field experiment was carried out during the 2005/2006 growing season, with rice cultivated under the conventional system. Treatments consisted of six rice cultivars differing in life cycle duration and ten barnyardgrass plant populations. Variables were evaluated 28 days after rice emergence. The rectangular hyperbolic model was tested to describe the relationship between rice grain yield loss and explicative variables in plants, dry weight, soil coverage and leaf area. Rice grain yield losses due to barnyardgrass interference may be satisfactorily estimated by the hyperbolic model. IRGA 421, 416, and 417 rice cultivars were the most competitive, attaining suitable data fitting to the model tested for all evaluated variables. The variable Barnyardgrass plant population presents better adjustment to the model than do shoot dry matter mass, soil cover, or leaf area.
\end{abstract}

Keywords: competition, empirical model, explicative variables.

1 Recebido para publicação em 9.2.2007 e na forma revisada em 25.10.2007.

Parte da Dissertação de Mestrado do Primeiro autor apresentada ao Programa de Pós-Graduação em Fitossanidade da UFPel, Pelotas-RS; ${ }^{2}$ Eng ${ }^{\circ}$-Agro , aluno do Programa de Pós-Graduação em Fitossanidade da Universidade Federal de Pelotas-UFPel, Caixa Postal 354, 96010-900, Capão do Leão-RS, <galonleandro@ig.com.br>; ${ }^{3}$ Eng ${ }^{\circ}-$ Agr ${ }^{\circ}$, Dr. Prof. da Faculdade de Agronomia Eliseu Maciel da UFPel (Bolsista do CNPq); ${ }^{4}$ Aluno de graduação da Faculdade de Agronomia Eliseu Maciel-UFPel. 


\section{INTRODUÇÃO}

$\mathrm{O}$ arroz irrigado é uma das culturas mais importantes para o Estado do Rio Grande do Sul (RS), com produção aproximada de 6,23 milhões de toneladas, em área cultivada de aproximadamente 1,03 milhão de hectare e com produtividade média de $6 \mathrm{t} \mathrm{ha}^{-1}$ (Gomes, 2004). No entanto, essa produtividade alcançada nas lavouras gaúchas está aquém daquela das lavouras que adotam alto nivel tecnológico e do potencial obtido nas áreas experimentais. Um dos fatores responsáveis pela reduzida produtividade das lavouras decorre do controle insatisfatório das plantas daninhas.

Dentre as espécies que mais infestam e causam dano à cultura do arroz irrigado no RS, destacam-se as pertencentes ao gênero Echinochloa (Kissmann, 1997). O autor relata que a identificação precisa das espécies pertencentes a esse gênero é dificil, devido ao grande polimorfismo dentro da mesma espécie e, ainda, à ocorrência de cruzamentos naturais, produzindo-se híbridos que não se encaixam em nenhuma posição definida.

A principal forma de interferência do capim-arroz sobre o arroz cultivado é a competição por recursos do meio. A cultura do arroz, quando irrigada e adubada adequadamente, passa a ter no recurso luz a forma mais importante de competição (Fischer, 1985). A competição por luz se intensifica quando as plantas daninhas alcançam desenvolvimento suficiente e passam a sombrear as cultivadas. Fica implícito que as espécies que se desenvolvem simultaneamente e com maior rapidez em altura e área foliar competem mais eficientemente pela luz (Fischer 1985; Walker et al., 1988).

Em estudos de competição de genótipos de arroz com plantas daninhas, verificou-se que o índice de área foliar (IAF) e o número de afilhos (CIAT, 1995); a área foliar e o número de afilhos (Fischer et al., 1997); a estatura de planta e o IAF (Garrity et al., 1992); e a massa da matéria seca (Ni et al., 2000) foram as variáveis mais relacionadas com alta capacidade competitiva dos cultivares. No entanto, a determinação das características da planta que contribuem para a competitividade é tarefa dificil, já que não há padrões simples para sua seleção e, além disso, a habilidade competitiva de cultivares pode ser alterada por práticas agronômicas (Ni et al., 2000).

Com o desenvolvimento de cultivares modernos de arroz (semianãs), o problema das plantas daninhas tornou-se ainda mais sério. Os cultivares modernos permitem passar maior quantidade de luz através da folhagem, favorecendo a emergência e o crescimento das plantas daninhas (Garrity et al., 1992). Assim, pode-se concluir que, dentro do contexto morfológico da planta de arroz, as características que mais influenciariam a habilidade competitiva com as plantas daninhas são IAF, massa da matéria seca, cobertura do solo, estatura de planta e capacidade de afilhamento.

A adoção de práticas de manejo do capimarroz (Echinochloa spp.), com o uso de cultivares de arroz competitivos que possam se desenvolver com maior rapidez que a planta daninha, constitui uma opção promissora para reduzir o uso de herbicidas.

Várias pesquisas relatam existir variabilidade na habilidade competitiva de cultivares de arroz com plantas daninhas pelos recursos do meio, devido ao conjunto de características morfológicas e fisiológicas desses cultivares (Ni et al., 2000; Balbinot Jr. et al., 2003; Fleck et al., 2004). O aumento da capacidade de competição de cultivares com plantas daninhas pode ser atribuído aos fatores: antecipação da época de emergência, maior vigor de plântulas, taxas de expansões foliares maiores, desenvolvimento acelerado do dossel, maior estatura de planta, ciclo de desenvolvimento precoce e aumento do tamanho de raizes (Berkowitz, 1988). Nesse sentido, ao usar genótipos de maior habilidade competitiva, pode-se dificultar ou até reduzir a intensidade de competição de plantas daninhas com a cultura.

Estratégias alternativas para melhorar o manejo de plantas daninhas podem ser obtidas pela utilização de modelos empíricos de competição com as culturas, os quais descrevem a resposta da perda de produtividade da cultura em relação a uma ou mais variáveis que caracterizam a infestação das plantas daninhas.

Por meio da equação não-linear da hipérbole retangular, pode-se fazer uma relação entre perda de produtividade da cultura e variáveis explicativas, como população, massa 
da matéria seca, cobertura do solo e área foliar das plantas daninhas (Cousens, 1985). De acordo com esse autor, o modelo da hipérbole contém parâmetros que apresentam significado biológico e agronômico, os quais podem ser usados como índices de competitividade. Desse modo, a redução do ciclo de desenvolvimento de cultivares de arroz incrementa a habilidade competitiva da cultura em relação ao capim-arroz.

Objetivou-se com o trabalho avaliar a influência de cultivares de arroz irrigado no grau de interferência do capim-arroz com a cultura e comparar variáveis explicativas, visando identificar a que propicia melhor ajuste dos dados ao modelo.

\section{MATERIAL E MÉTODOS}

O experimento foi conduzido a campo, em área experimental do Centro Agropecuário da Palma (CAP) da Universidade Federal de Pelotas (UFPel), no município de Capão do LeãoRS, ano agrícola 2005/06. O solo da área experimental é classificado como Planossolo Hidromórfico Eutrófico solódico, pertencente à Unidade de Mapeamento Pelotas (Embrapa, 1999).

A adubação de manutenção foi realizada conforme as recomendações para a cultura (SOSBAI, 2005). O experimento foi instalado em sistema de cultivo convencional, com aração e gradagem, em delineamento experimental completamente casualizado, sem repetição. Cada unidade experimental (parcela) foi composta por área de $11,05 \mathrm{~m}^{2}(5,0 \times 2,21 \mathrm{~m})$, constando de 13 fileiras de arroz espaçadas de 0,17 m. Os tratamentos foram constituídos de seis cultivares de arroz e 10 populações da planta competidora - capim-arroz. O capim-arroz foi estabelecido em 10 densidades, obtendose populações máximas de 622, 238, 396, 532, 888 e 434 plantas $\mathrm{m}^{-2}$ para os cultivares BRSAtalanta e IRGA 421 (ciclo muito curto), IRGA 416, IRGA 417 e Avaxi (ciclo curto) ou BRS-Fronteira (ciclo médio), respectivamente (SOSBAI, 2005).

As diferenças observadas nas populações de capim-arroz em competição com os cultivares podem ser decorrentes de suas diferenças morfofisiológicas, as quais interferem na interceptação e utilização da radiação solar, afetando conseqüentemente a habilidade competitiva da cultura.

Os cultivares de arroz foram semeados em 10.11.2005, utilizando-se semeadora-adubadora e densidade de semeadura de $125 \mathrm{~kg} \mathrm{ha}^{-1}$, o que proporcionou estabelecimento de população aproximada de 400 plantas $\mathrm{m}^{-2}$, à exceção do híbrido Avaxi, em que a densidade de semeadura foi de $50 \mathrm{~kg} \mathrm{ha}^{-1}$, obtendo-se população aproximada de 160 plantas $\mathrm{m}^{-2}$ (SOSBAI, 2005).

A emergência da cultura ocorreu 18 dias após a semeadura; esse atraso deve-se ao longo período de estiagem que ocorreu na estação de crescimento, sendo necessário saturar o solo (banho) após a semeadura, para facilitar o estabelecimento da cultura e das plantas daninhas. A irrigação por inundação permanente da área experimental iniciou-se aos 20 dias após a emergência (DAE) da cultura, permanecendo até a colheita dos cultivares. As demais práticas de manejo utilizadas foram aquelas recomendadas pela pesquisa para a cultura do arroz irrigado (SOSBAI, 2005).

A população da espécie competidora foi estabelecida a partir do banco de sementes do solo, pela aplicação do herbicida cyhalofop-butyl $\left(270 \mathrm{~g} \mathrm{ha}^{-1}\right)+$ adjuvante Iharol $\left(1,5 \mathrm{~L} \mathrm{ha}^{-1}\right)$, quando a cultura se encontrava nos estádios fenológicos $V_{2}$ a $V_{3}(15 \mathrm{DAE})$ e a planta daninha no estádio de 2 a 3 folhas. A época foi escolhida em razão de ser a mais adequada para aplicação de herbicidas em pós-emergência. As plantas de capim-arroz foram protegidas com copos ou placas (lâminas) plásticas, para que não sofressem injúrias do herbicida.

O herbicida cyhalofop-butyl foi utilizado por apresentar bom controle do capim-arroz, ser altamente seletivo para a cultura e também por não apresentar persistência no solo e/ou na água (Rodrigues \& Almeida, 2005).

A quantificação de população das plantas (PP) de capim-arroz, massa da matéria seca da parte aérea (MMSPA), área foliar (AF) ou cobertura do solo (CS) foi feita aos 28 DAE da cultura. Para determinação da variável explicativa $\mathrm{PP}$, foram realizadas contagens das plantas presentes em duas áreas de $0,25 \mathrm{~m}^{2}$ $(0,5 \times 0,5 \mathrm{~m})$ por parcela. A MMSPA das plantas de capim-arroz $\left(\mathrm{g} \mathrm{m}^{-2}\right)$ foi determinada pelas coletas das plantas contidas em área de $0,25 \mathrm{~m}^{2}$ por parcela e secagem em estufa a 
$65^{\circ} \mathrm{C}$, até peso constante. A quantificação da AF da planta competidora foi feita com um integrador eletrônico de área foliar, utilizando as folhas das plantas colhidas para avaliação da MMSPA. A CS por plantas de capim-arroz foi avaliada visualmente, de modo individual, por dois avaliadores, utilizando-se escala percentual, na qual a nota zero corresponde à ausência de cobertura do solo e a nota 100 representa cobertura total do solo.

A produtividade de grãos do arroz foi quantificada pela colheita da área central das parcelas em área de $4,5 \mathrm{~m}^{2}$ (3 x 1,5 m), sendo realizada de acordo com a maturação de cada cultivar, ou seja, quando o teor de umidade dos grãos aproximou-se de $22 \%$. Após pesagem dos grãos, foi determinada sua umidade e, posteriormente, os pesos foram uniformizados para $13 \%$ de umidade.

Com os dados da produtividade de grãos, foram calculadas as perdas percentuais em relação às parcelas mantidas sem infestação (testemunhas), de acordo com a Equação 1:

$$
\text { Perda }(\%)=\left[\frac{R a-R b}{R a}\right] \times 100 \quad \text { Equação 1 }
$$

em que: $R a$ e $R b$ : produtividade da cultura sem ou com presença de capim-arroz, respectivamente.

Anteriormente à análise dos dados, os valores da MMSPA $\left(\mathrm{g} \mathrm{m}^{-2}\right)$, CS (\%) ou AF $\left(\mathrm{cm}^{2}\right)$ foram multiplicados por 100 , dispensando-se assim o uso do fator de correção no modelo (Agostinetto et al., 2004a; Fleck et al., 2004). As relações entre perdas percentuais de produtividade do arroz cultivado, em função das variáveis explicativas $\mathrm{PP}, \mathrm{MMSPA}, \mathrm{CS}$ ou $\mathrm{AF}$ de capim-arroz, foram calculadas separadamente para cada cultivar, utilizando-se o modelo de regressão não-linear derivada da hipérbole retangular, proposto por Cousens em 1985 (Equação 2):

$$
\mathrm{Pp}=\frac{(i * \mathrm{X})}{\left(1+\left(\frac{i}{a}\right) * \mathrm{X}\right.}
$$

Equação 2

em que: $\mathrm{Pp}=$ perda de produtividade $(\%) ; X=$ população, massa da matéria seca da parte aérea, cobertura foliar ou área foliar relativas ao competidor; e $i$ e $a=$ perdas de produtividade
(\%) por unidade de plantas de capim-arroz quando o valor da variável se aproxima de zero ou quando tende ao infinito, respectivamente.

O ajuste dos dados ao modelo foi realizado através do procedimento Proc Nlin do programa computacional SAS (SAS, 1989). Para o procedimento de cálculos, utilizou-se o método de Gauss-Newton, o qual, por sucessivas iterações, estima os valores dos parâmetros nos quais a soma dos quadrados dos desvios das observações, em relação aos ajustados, é mínima (Ratkowsky, 1983).

$O$ valor da estatística $F(P \leq 5 \%)$ foi utilizado como critério de ajuste dos dados ao modelo. O critério de aceitação do ajuste dos dados ao modelo baseou-se no maior valor do coeficiente de determinação $\left(\mathrm{R}^{2}\right)$ e no menor valor do quadrado médio do resíduo (QMR).

\section{RESULTADOS E DISCUSSÃO}

Os valores da estatística $F$ foram significativos para as variáveis explicativas PP, MMSPA, CS ou AF do capim-arroz, em todos os cultivares de arroz estudados (Figuras 1, 2, 3 ou 4). Em todos os cultivares de arroz, o modelo da hipérbole retangular ajustou-se adequadamente aos dados, à exceção da variável CS para o cultivar de arroz IRGA 416, a qual apresentou baixo valor de $\mathrm{R}^{2}$ e elevado QMR, o que caracteriza baixo ajuste ao modelo.

Os resultados demonstram, para todas as variáveis, que os valores estimados para o parâmetro $i$ tenderam a ser menores nos cultivares de arroz IRGA 421 (ciclo muito curto) ou IRGA 416 ou 417 (ciclo curto) (Figuras 1, 2, 3 ou 4). Já a menor competitividade do cultivar Avaxi (ciclo curto) pode ser decorrente da menor densidade de semeadura, o que permitiu maior passagem de radiação e conseqüente novo fluxo de emergência das plantas de capimarroz, após a determinação das variáveis explicativas (28 DAE). De acordo com Fleck et al. (2003), genótipos de arroz que apresentam baixa cobertura do solo permitem maior penetração de luz no dossel da comunidade e, conseqüentemente, menor competitividade com as plantas daninhas.

A menor competitividade do cultivar BRSAtalanta (ciclo muito curto), comparativamente ao IRGA 421, pode ser decorrente de sua menor estatura (Terres et al., 1999). Dentre as 

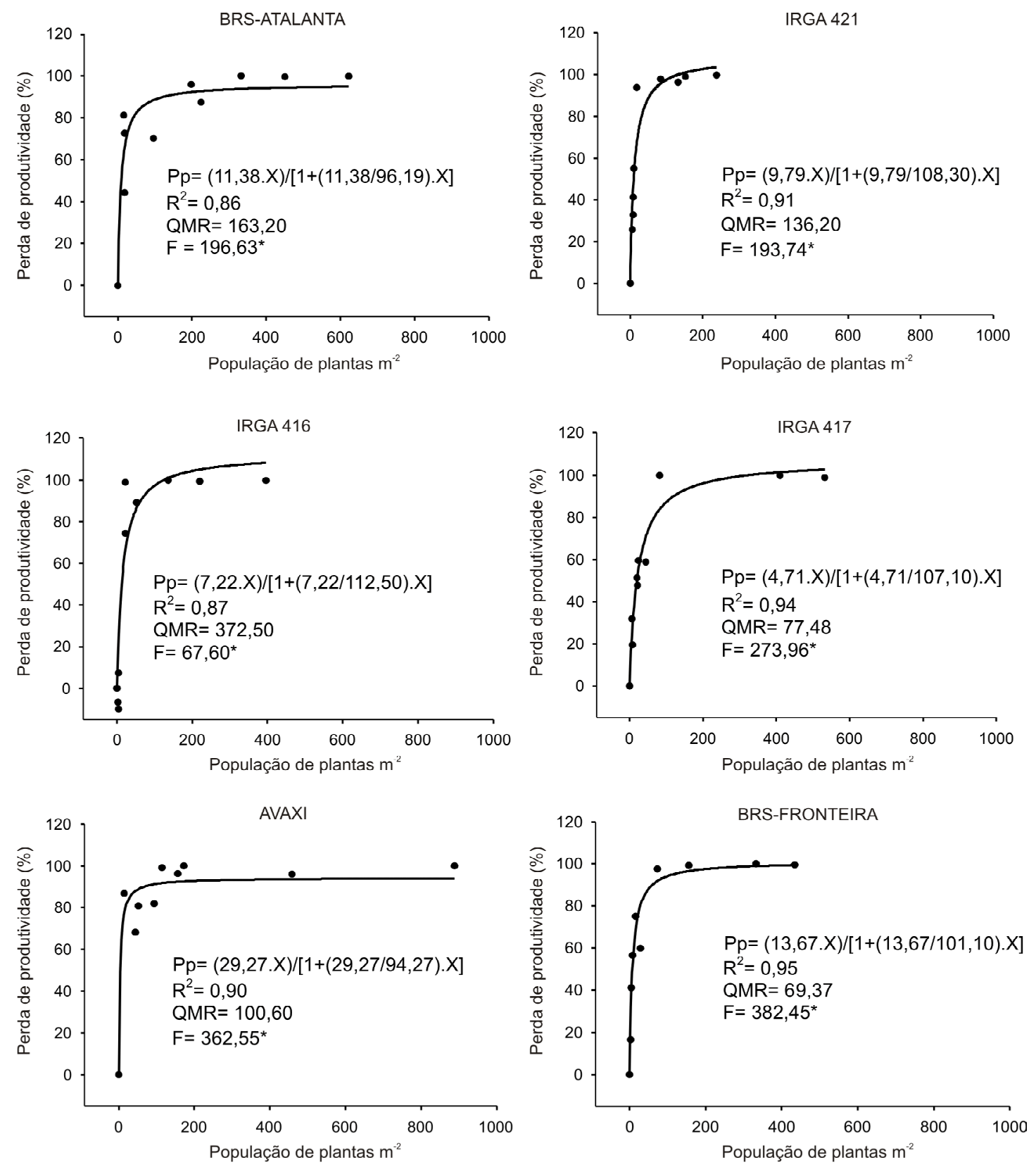

Figura 1 - Perda de produtividade (Pp) de cultivares de arroz em função da população de capim-arroz aos 28 DAE - CAP/UFPel, Capão do Leão-RS, 2005/06.( $\mathrm{R}^{2}$ : coeficiente de determinação; QMR: quadrado médio do resíduo; * significativo a 5\%.

características morfológicas, a estatura de planta é a que mais fortemente se relaciona com o baixo desenvolvimento de plantas daninhas no início do ciclo, devido ao sombreamento imposto pela cultura, competindo assim mais eficientemente pelo recurso luz (Garrity et al., 1992).
Em geral, o cultivar BRS-Fronteira (ciclo médio) apresentou baixa competitividade em relação às variáveis avaliadas, isso pode ter ocorrido em razão de ele apresentar crescimento inicial mais lento quando comparado aos de menor ciclo. O cultivar BRS-Fronteira é proveniente de cruzamentos de variedades 

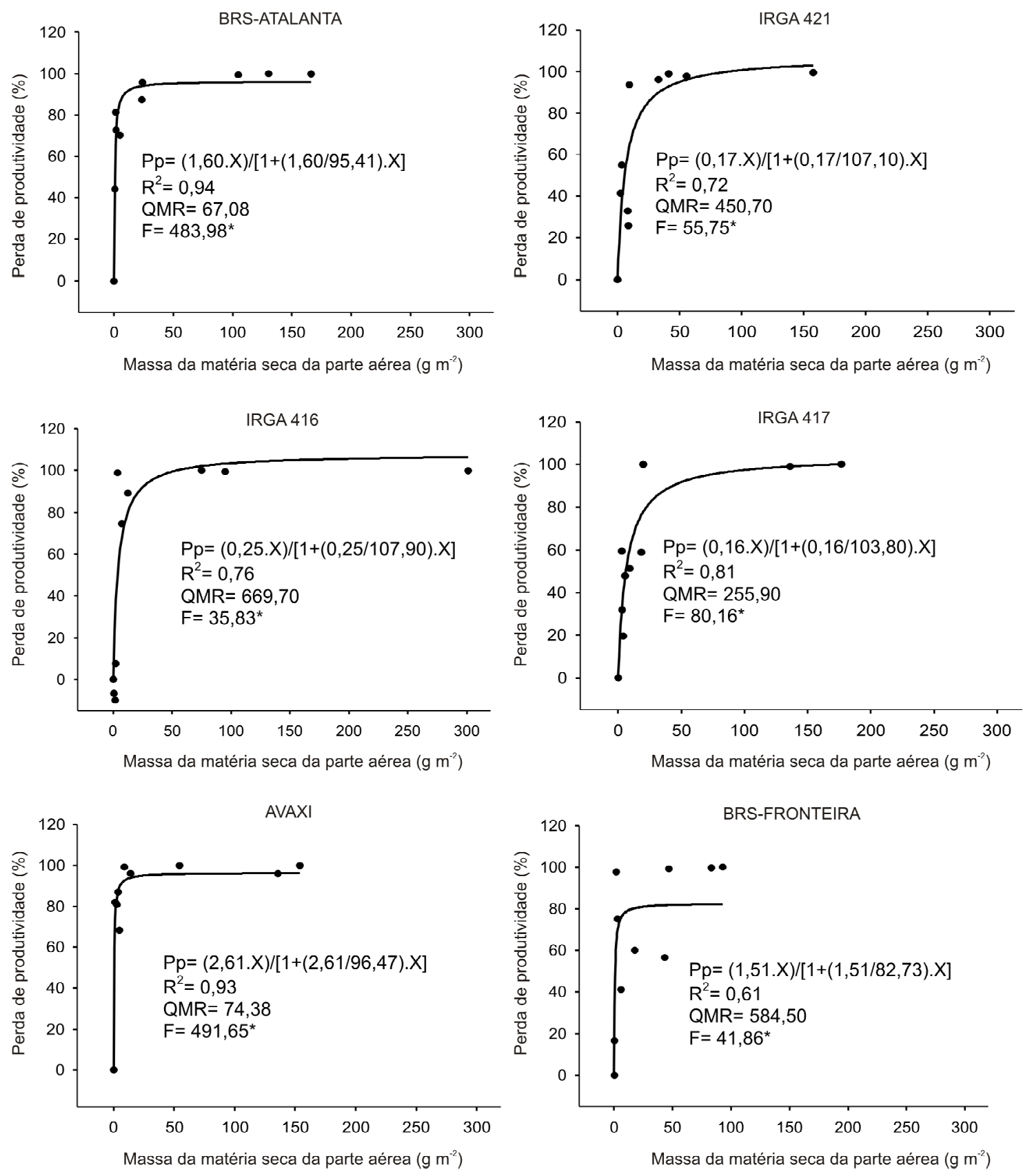

Figura 2 - Perda de produtividade $(\mathrm{Pp})$ de cultivares de arroz em função da massa da matéria seca da parte aérea de capim-arroz aos 28 DAE - CAP/UFPel, Capão do Leão-RS, 2005/06. (R²: coeficiente de determinação; QMR: quadrado médio do resíduo; $*$ significativo a $5 \%$.

japonica e, quando em competição com o capimarroz, no início do ciclo de desenvolvimento, poderá apresentar baixa habilidade competitiva. De acordo com Rosso et al. (2001), geralmente, cultivares de arroz provenientes de germoplasmas japonica são influenciados negativamente por estresses bióticos ou abióticos. Nesse sentido, Balbinot Jr. et al. (2003), ao trabalharem com o cultivar de origem japonica Bluebelle, em competição com o genó tipo EEA406 , constataram que aquele apresenta baixa velocidade de crescimento e reduzida capacidade de cobertura do solo, permitindo assim el evada penetração de luz pelo dossel, 

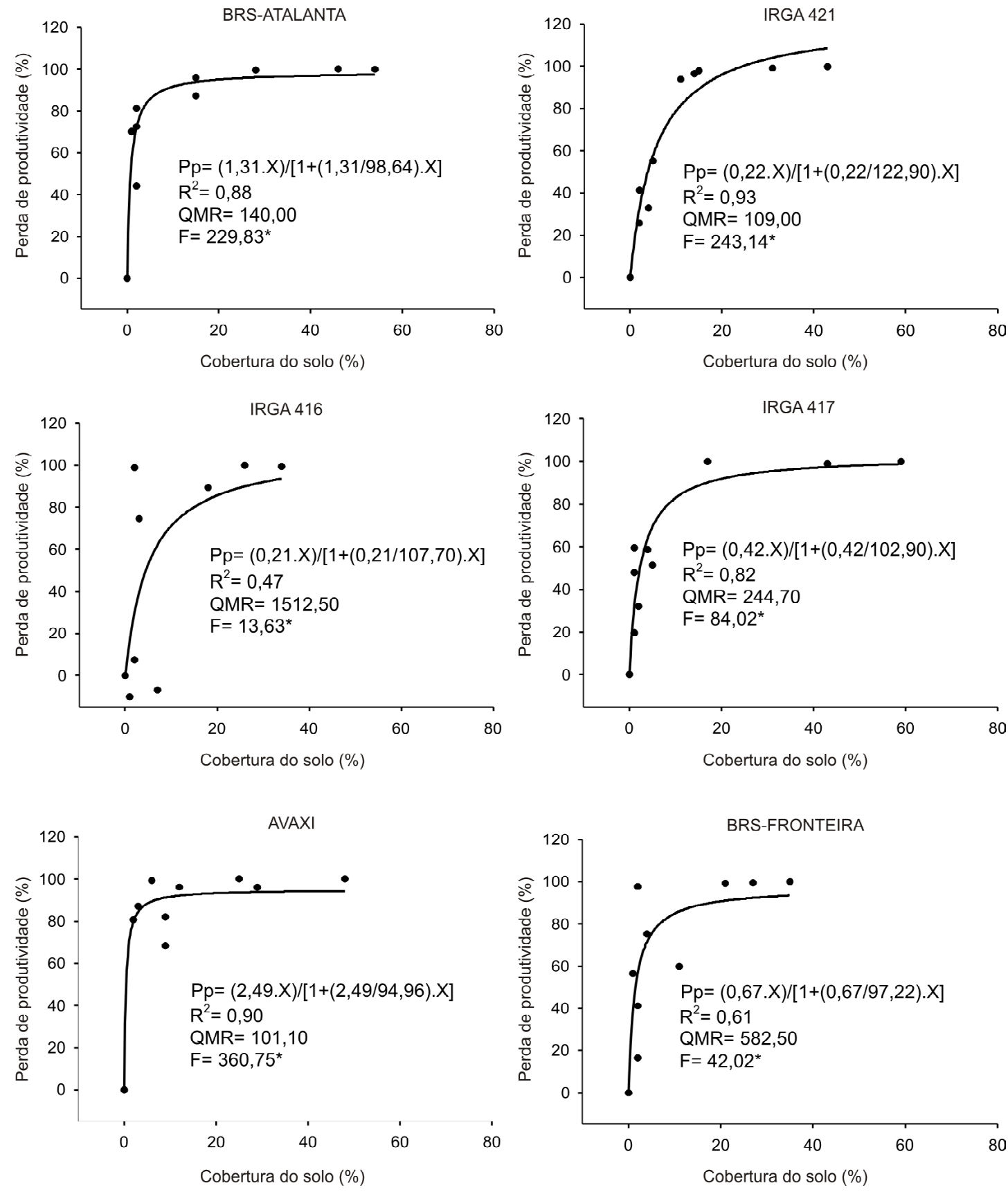

Figura 3 - Perda de produtividade (Pp) de cultivares de arroz em função da cobertura do solo pela folhagem de capim-arroz aos 28 DAE - CAP/UFPel, Capão do Leão-RS, 2005/06. (R²: coeficiente de determinação; QMR: quadrado médio do resíduo; * significativo a $5 \%$.

demonstrando menor capacidade competitiva com as plantas daninhas já na fase vegetativa.

Por ser o parâmetro $i$ um índice usado para comparar a competitividade relativa entre espécies (Swinton et al., 1994) constataram-se valores diferenciados para os cultivares de arroz nas variáveis explicativas testadas
(Figuras 1, 2, 3 ou 4). A comparação entre genótipos considerando o parâmetro $i$, na média das quatro variáveis explicativas (PP, MMSPA, CS ou $\mathrm{AF}$ ), demonstrou que a ordem de colocação em relação à competitividade dos cultivares foi: IRGA $417>$ IRGA $416>$ IRGA $421>$ BRSAtalanta $>$ BRS-Fronteira > Avaxi. As 

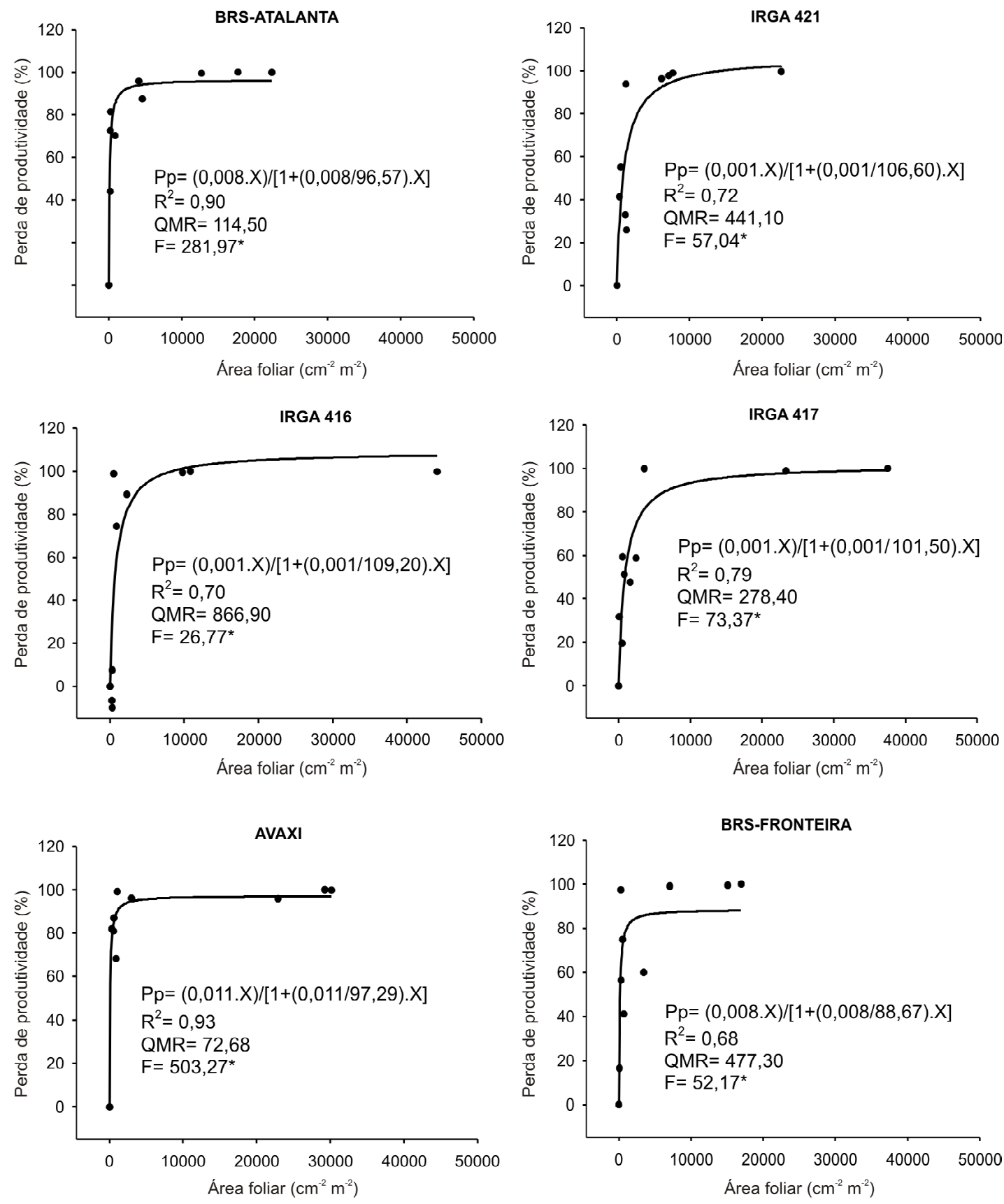

Figura 4 - Perda de produtividade (Pp) de cultivares de arroz em função da área foliar de capim-arroz aos 28 DAE - CAP/UFPel, Capão do Leão-RS, 2005/06. (R²: coeficiente de determinação; QMR: quadrado médio do resíduo; * significativo a 5\%.

diferenças observadas entre os resultados dos cultivares pode ser devido às características morfofisiológicas destes ou a ocorrência de elevado erro-padrão na estimativa do parâmetro $i$, podendo ser atribuído à variabilidade associada com experimentação de campo e a plasticidade fenotípica da cultura (Dieleman et al.,
1995). Assim, essa variabilidade pode dificultar a estimativa correta das perdas de produtividade em baixas densidades de plantas de capim-arroz.

Em todas as variáveis explicativas, observou-se que cultivares de mesmo ciclo de 
crescimento apresentam valores diferenciados do parâmetro $i$ (Figuras 1, 2, 3 ou 4). Isso demonstra que os genótipos de arroz respondem de modo distinto à competição com o capim-arroz. De acordo com Balbinot Jr. et al. (2003), isso é decorrente do conjunto de características morfofisiológicas de cada genótipo, que define a capacidade em competir com plantas daninhas pelos recursos disponiveis no ambiente. Outra explicação está relacionada à estatura entre os diferentes cultivares, característica esta importante na competição por luz, a qual afeta a produtividade dependendo do estádio em que passa a ocorrer o sombreamento, relativamente à definição dos componentes da produtividade (Agostinetto et al., 2004b). Ainda segundo estes autores, as folhas sombreadas recebem basicamente luz refletida e de menor intensidade, o que causará diminuição gradativa da taxa fotossintética à medida que se aproxima do solo.

Comparando os cultivares de arroz para a variável $\mathrm{PP}$, com base na perda unitária (i), observaram-se perdas de produtividades de 10 , $9,7,5,22$ e $12 \%$ para ao cultivares BRS-Atalanta, IRGA 421 (ciclo muito curto), IRGA 416, 417 e Avaxi (ciclo curto) ou BRS-Fronteira (ciclo médio), respectivamente (Figura 1). De acordo com Fleck et al. (2004), cultivares de arroz com ciclos de desenvolvimento diferentes respondem de maneira independente em situações de competição interespecífica, com reflexos na produtividade de grãos de forma diferenciada.

As estimativas do parâmetro $a$, independentemente da variável explicativa, foram superestimadas pelo modelo, com perdas de produtividade superiores a $100 \%$, para os cultivares IRGA 421 (ciclo muito curto), IRGA 416 ou 417 (ciclo curto) (Figuras 1, 2, 3 ou 4). Esses resultados podem ser decorrentes de as maiores populações de plantas de capim-arroz terem sido insuficientes para estimar adequadamente a perda máxima de produtividade. De acordo com Cousens (1991), para obtenção de estimativa confiável para o parâmetro $a$, tornase necessário incluir no experimento populações muito elevadas de plantas daninhas, acima daquelas comumente encontradas em lavoura.

Uma opção para evitar que as perdas de produtividades sejam superestimadas seria limitar a perda máxima em $100 \%$. Contudo, a limitação influenciará a estimativa do parâmetro $i$, podendo resultar em menor previsibilidade no modelo da hipérbole retangular (Streibig et al., 1989). Além disso, perdas de produtividade superiores a 100\% são biologicamente irreais e ocorrem quando a amplitude de populações de plantas daninhas é excessivamente estreita e/ou quando os maiores valores de população não são suficientes para produzir respostas assintóticas de perda de produtividade (Cousens, 1985; Yenish et al., 1997; Askew \& Wilcut, 2001).

Os resultados demonstram que o cultivar BRS-Atalanta apresentou perdas máximas de produtividade inferiores a $100 \%$ em todas as variáveis explicativas, diferentemente do cultivar IRGA 421 que apresenta mesmo ciclo de desenvolvimento (Figuras 1, 2, 3 ou 4). Isso pode ser decorrente da BRS-Atalanta normalmente apresentar potencial produtivo cerca de $20 \%$ superior ao de cultivares de mesmo ciclo (SOSBAI, 2005). Para o cultivar Avaxi, o menor valor do parâmetro $a$ em relação as demais de mesmo ciclo (IRGA 416 ou 417) pode ser atribuído à grande capacidade de emissão de afilhos, aumentando sua plasticidade de resposta (Wu et al., 1998). Segundo essee autores, existe efeito compensatório entre afilhos e os componentes de produtividade, que promove a estabilidade na produtividade de grãos para um dado genótipo numa faixa de populações de plantas.

Em geral, observou-se que o cultivar BRSFronteira (ciclo médio) apresentou perda máxima de produtividade inferior a $100 \%$, em todas as variáveis explicativas estudadas (Figuras 1, 2, 3 ou 4). Esse resultado pode ser atribuído à sua maior fase vegetativa, ou seja, ele teria a capacidade de potencializar a produtividade de grãos pela melhor utilização do nitrogênio e da radiação solar, resultando em maior produtividade de grãos, se comparado aos cultivares de ciclo mais curto (Khush, 1995). Outro fator que pode corroborar isso é o fato de cultivares de arroz com ciclos de desenvolvimento mais longos apresentarem incrementos mais expressivos em área foliar e, desse modo, serem mais competitivos com as plantas daninhas (Fleck et al., 2003).

A comparação entre as variáveis explicativas para todas os cultivares, em geral, demonstrou melhor ajuste ao modelo para as variáveis 
$\mathrm{PP}>\mathrm{MMSPA}>\mathrm{AF}>\mathrm{CS}$, considerando os maiores valores médios do $\mathrm{R}^{2}$ e os menores valores médios do QMR (Figuras 1, 2, 3 ou 4). Já a comparação entre as variáveis explicativas MMSPA, $\mathrm{CS}$ e $\mathrm{AF}$, como variáveis independentes no modelo de previsão das perdas de produtividade, em geral, demonstrou que a AF apresentou melhor ajuste e pode ser usada em substituição à variável PP. De modo semelhante, Vitta \& Fernandez Quintanilla (1996) observaram que o modelo que incorporou a variável $\mathrm{AF}$ foi tão preciso quanto o da população de plantas daninhas. No entanto, cabe ressaltar que a variável $\mathrm{AF}$ apresentou valores estimados extremamente baixos para perdas unitárias de produtividade de grãos. Além disso, a AF não é fácil de medir e sua determinação é demorada, trabalhosa e destrutiva (Vitta \& Fernandez Quintanilla, 1996).

Considerando-se a produtividade média do arroz irrigado no Estado do RS de $5.580 \mathrm{~kg} \mathrm{ha}^{-1}$ (IRGA, 2006), o preço médio de 9,0 dólares $50 \mathrm{~kg}^{-1}$ e o custo de controle de capim-arroz de 87 dólares ha-1, estima-se que o custo de controle equivale a $9 \%$ da produção (IRGA, 2006). Assim, considerando que a presença de uma planta de capim-arroz $\mathrm{m}^{-2}$ ocasionará perdas de produtividades de $10,9,7,5,22$ e $12 \%$, respectivamente para os cultivares de arroz BRSAtalanta, IRGA 421, IRGA 416, 417, Avaxi ou BRS-Fronteira (Figura 1), somente os cultivares IRGA 421, 416 ou 417 apresentam perdas de produtividade por interferência abaixo ou equivalentes ao valor do custo de controle. Esses resultados indicam que o capim-arroz é muito competitivo, mesmo em baixas populações, e que medidas de controles que eliminem até $99 \%$ da infestação podem não ser suficientes para evitar perdas de produtividades que justifiquem a adoção de medidas de controle.

Os resultados demonstram que o modelo de regressão não-linear da hipérbole retangular estima adequadamente as perdas de produtividade de arroz irrigado na presença das plantas de capim-arroz. Os cultivares de arroz IRGA 421, IRGA 416 ou IRGA 417 apresentam maior habilidade competitiva com o capim-arroz em relação aos cultivares BRS-Atalanta, Avaxi ou BRS-Fronteira. A variável PP apresentou melhor ajuste ao modelo, embora AF tenha mostrado potencial para substituí-la na previsão da perda de produtividade de grãos de arroz irrigado, devido à interferência do capim-arroz.

\section{AGRADECIMENTOS}

À Coordenação de Aperfeiçoamento de Pessoal de Nivel Superior (CAPES) e à Fundação de Amparo à Pesquisa do Estado do Rio Grande do Sul (FAPERGS), e ao Conselho Nacional de Desenvolvimento Científico e Tecnológico (CNPq), pelas concessão de bolsas.

\section{LITERATURA CITADA}

AGOSTINETTO, D. et al. Perdas de rendimento de grãos na cultura de arroz irrigado em função da população de plantas e da época relativa de emergência de arroz-vermelho ou de seu genótipo simulador de infestação de arroz-vermelho. Planta Daninha, v. 22, p. 175-183, 2004a.

AGOSTINETTO, D. et al. Influência de cultivares de arroz e épocas da adubação nitrogenada nas relações de interferência da cultura com cultivar simulador de infestação de arrozvermelho. Planta Daninha, v. 22, p. 185-193, 2004b.

ASKEW, S. D.; WILCUT, J. W. Tropic croton interference in cotton. Weed Sci., v. 49, p. 184-189, 2001.

BALBINOT JR., A. A. et al. Competitividade de cultivares de arroz irrigado com cultivar simuladora de arroz-vermelho. Pesq. Agropec. Bras. , v. 38, p. 53-59, 2003.

BERKOWITZ, A. R. Competition for resources in weedcrop mixtures. In: ALTIERI, M. A.; LIEBMAN, M. (Eds). Weed management in agroecosystems: ecological approaches. Boca Raton: CRC Press, 1988. p. 89-120.

CIAT. Rice program. Annual report, Cali: 1995. 78 p.

COUSENS, R. An empirical model relating crop yield to weed and crop density and a statistical comparison with other models. J. Agric. Sci., v. 105, p. 513-521, 1985.

COUSENS, R. Aspects of the design and interpretation of competition (interference) experiments. Weed Technol., v. 5, p. 664-673, 1991.

DIELEMAN, A. et al. Empirical models of pigweed (Amaranthus spp.) interference in soybean (Glycine max). Weed Sci., v.43, p. 612-61 8, 1995.

EMPRESA BRASILEIRA DE PESQUISA AGROPECUÁRIA - EMBRAPA. Centro Nacional de Pesquisa Agropecuária de Solos. Sistema brasileiro de classificação de solos. Rio de Janeiro: 1999. 412 p. 
FISCHER, A. J. Aspectos de la interferencia entre las mazelas y los cultivos. In: SHENK, M.; FISCHER, A. J.; BERNAL, V. (Eds.). Principios básicos sobre el manejo de mazelas. El Zamorano: Escuela Agrícola Panamericana, 1985. p. 21-40. (Publicación MIPH-EAP, 65).

FISCHER, A. J.; RAMÍREZ, H. V.; LOZANO, J. Suppression of junglerice (Echinochlo a colona (L.) Link) by irrigated rice cultivars in Latin America. Agron. J., v. 89, p. 516-521, 1997.

FLECK, N. G. et al. Características de plantas de cultivares de arroz irrigado relacionadas à habilidade competitiva com plantas concorrentes. Planta Daninha, v. 21, p. 97-104, 2003.

FLECK, N. G. et al. Interferência de plantas concorrentes em arroz irrigado modificada por métodos culturais. Planta

Daninha, v. 22, p. 19-28, 2004.

GARRITY, D. P.; MOVILLON, M.; MOODY, K. Differential weed suppression ability in upland rice cultivars. Agron. J., v. 84, p. 586-591, 1992.

GOMES, A. S.; MAGAlHÃES JR., A. M. Arroz irrigado no Sul do Brasil. Brasília: Embrapa Informação Tecnológica, 2004. 899 p.

INSTITUTO RIO-GRANDENSE DO ARROZ - IRGA. Arroz irrigado no RS - área, produção e rendimento. Disponível em: $<$ http://www.irga.rs.gov.br $>$. Acesso em: 05 out. 2006.

KHUSH, G. S. Breaking the yield frontier of rice. Geojournal, v. 35, p. 329-332, 1995.

KISSMANN, K. G. Plantas infestantes e nocivas. 2.ed. São Paulo: BASF, 1997. Tomo I. 825 p.

NI, H. et al. Oryza sativa plant traits conferring competitive ability against weeds. Weed Sci., v. 48, p. 200-204, 2000.

RATKOWSKY, D. A. Nonlinear regression modeling: a unified practical approach. New York: Marcel Dekker, 1983. p. $135-154$.

RODRIGUES, B. N.; ALMEIDA, F. S. Guia de herbicidas. 5. ed. Londrina, 2005. 592 p.
ROSSO, A. F. et al. Avaliação de genótipos de arroz para a tolerância ao frio na fase de germinação. In: CONGRESSO BRASILEIRO DE ARROZ IRRIGADO, 2., REUNIÃO DA CULTURA DO ARROZ IRRIGADO, 24., 2001, Porto Alegre. Anais... Porto Alegre: Instituto Rio Grandense do Arroz, 2001. p. 83-84.

INSTITUTE STATISTICAL ANALYSIS SYSTEM - SAS. User's guide: version 6.4.ed. Cary: 1989. 846 p.

SOCIEDADE SUL-BRASILEIRA DE ARROZ IRRIGADO - SOSBAI. Arroz irrigado: Recomendações técnicas da pesquisa para o Sul do Brasil. Santa Maria: Universidade Federal de Santa Maria, 2005. 159 p.

STREIBIG, J. C. et al. Estimation of thresholds for weed control in Australian cereals. Weed Res., v. 29, p. 117-126, 1989.

SWINTON, S. M. et al. Estimation of crop yield loss due to interference by multiple weed species. Weed Sci., v. 42, p. 103-109, 1994.

TERRES, A. L. S. et al. Melhoramento genético de arroz irrigado na Embrapa Clima Temperado: 10. BRS-Firmeza e BRS-Atalanta, novas cultivares para a oricultura gaúcha. In: CONGRESSO BRASILEIRO DE ARROZ IRRIGADO, 1., REUNIÃO DA CULTURA DO ARROZ IRRIGADO, 23., 1999, Pelotas. Anais... Pelotas: Embrapa Clima Temperado, 1999. p. 158-161.

VITTA, J. I.; FERNADEZ QUINTANILLA, C. Canopy measurements as predictors of weed-crop competition. Weed Sci., v. 44, p. 511-516, 1996.

WALKER, G. K.; BLACKSHAW, R. E.; DEKKER, J. Leaf area and competition for light between plant species using direct sunlight transmission. Weed Technol., v. 2, p. 159165, 1988.

WU, G.; WILSON, L.; McCLUNG, A. M. Contribution of rice tillers to dry matter accumulation and yield. Crop Sci., v. 90, p. 317-323, 1998.

YENISH, J. P. et al. Wheat (Triticum aestivum) yield reduction from common milkweed (Asclepias syriaca) competition. Weed Sci., v. 45, p. 127-131, 1997. 